\title{
A MODEL FOR POLAR CONTINENTAL SHELF-WATER MASS MODIFICATION
}

\author{
(Abstract) \\ by \\ R.W. Grumbine \\ (Department of the Geophysical Sciences, University of Chicago, 5734 S. Ellis Avenue, \\ Chicago, IL 60637, U.S.A.)
}

The process by which water flows from the surface ocean to the deep ocean is crucial in determining the structure and composition of the world ocean (Killworth, 1983). An important element in this process is the mechanism by which surface water on the Antarctic continental shelves becomes dense enough to sink to the abyssal ocean. These shelves are active sites of surface water modification because of the intense cooling and salt rejection due to sea-ice formation which occurs there during the winter.

Prior models of water mass modification on the Antarctic continental shelves have focused on either the wind-forced circulation (Killworth, 1973), or the density-forced circulation (Solomon, unpublished; Killworth, 1974). Solomon (unpublished) showed that the density-forced circulation alone is too weak to produce a flux of saline water to the deep sea which was consistent with observations. Killworth (1973) showed that the wind-forced circulation alone in the Weddell Sea was incapable of producing a large enough flux. In a complementary model of only the density-forced circulation, Killworth (1974) showed that the change in salinity of water parcels caused by regional density forcing was reasonable; but as in Solomon's (unpublished) model, the flux of modified water was too small. The result of these model studies was that either circulation alone, wind-forced or density-forced, is insufficient to produce the observed flux of saline shelf water. The conjecture based on the results of these studies was that, when combined, the density forcing determined the change of salinity in the shelf water and the wind-forced circulation determined the flux of the modified water.

To determine whether the combination of wind stress and density forcing is sufficient to produce a flux and salinity change consistent with observations, a simple model which responds to both forcings was developed. The model is essentially that used by Killworth (1974) with the addition of the flow forced by wind stress. A different density forcing is used because observations of the sea-ice cover (Zwally and others, 1983) suggest that the regions of coastal open water, and hence freezing, are much more localized than used in prior density-forced models. The localization of the density forcing was parameterized as being a Gaussian function of distance from and along the coast. The model (Grumbine, unpublished) predicts the velocity and salinity in two layers of equal depth in a square region with a flat bottom, subject to wind and density forcing. The east, south, and west boundaries represent coasts of an embayment analogous to the Weddell Sea continental shelf, with the continental shelf break in the middle, north-south, of the region, and an open northern boundary. The salinity is initially constant in each layer. The velocity is initialized to the equilibrium value of the wind-forced circulation. Then the salinity forcing is started and the evolution of the salinity fields is computed using the wind-forced velocity field and a diagnostically computed density-forced velocity field.

The model was run for three cases: wind stress forcing only, density forcing only, and wind stress and density forcing combined. The wind-forced circulation alone was incapable of producing a sufficient degree of water mass modification. With only density forcing, the change in salinity was consistent with observations, but the flux was too small. When the two forcings are combined, both the change in salinity and the flux of modified water are consistent with observations. The model is verified against the flux and composition values from observations by Foster and Carmack (1976) in the deep Weddell Sea. The observed flux value of 1 to $2.5 \times 10^{6} \mathrm{~m}^{3} \mathrm{~s}^{-1}$ corresponds to water with a mean salinity of $34.7 \%$. This is the salinity of the water which was able to reach the abyssal ocean off the Weddell Sea coast. Figure 1 gives the modelled seasonal cycle and annual mean of the equatorward flux of water which corresponds to a mean salinity of $34.7 \%$. The figure shows the flux for the last three years of a five- year run computed across the position of the continental slope. The mean annual flux of this modified water is $2.0 \times 10^{6} \mathrm{~m}^{3} \mathrm{~s}^{-1}$, compared to the observation of 1 to $2.5 \times 10^{6} \mathrm{~m}^{3} \mathrm{~s}^{-1}$. These results confirm the conjecture that the combination of wind and density forcing is sufficient to produce a degree of modification and flux of modified water consistent with observations.

\section{ACKNOWLEDGEMENTS}

This work was supported under NASA Student Training Grant NGT 50059, and NSF Grant DPP 85-09451. Editorial assistance from D. MacAyeal, A. Grumbine and D. Lindstrom is appreciated.

\section{REFERENCES}

Foster, T.D. and E.C. Carmack. 1976. Frontal zone mixing and Antarctic bottom water formation in the southern Weddell Sea. Deep-Sea Res., 23(4), 301-317.

Grumbine, R.W. Unpublished. Formation of high salinity shelf water on polar continental shelves. (Ph.D. thesis, University of Chicago, 1989.)

Killworth, P.D. 1973. A two-dimensional model for the formation of Antarctic bottom water. Deep-Sea Res., 20(11), 941-971.

Killworth, P.D. 1974. A baroclinic model of motions on Antarctic continental shelves. Deep-Sea Res., 21(10), 815837.

Killworth, P.D. 1983. Deep convection in the world ocean. Rev. Geophys. Space Phys., 21, 1-26.

Solomon, H. Unpublished. Large scale response of the ocean to sea ice formation. (Ph.D. thesis, Massachusetts Institute of Technology, 1969.)

Zwally, H.J., J.C. Comiso, and A.L. Gordon. 1985. Antarctic offshore leads and polynyas and oceanographic effects. In Jacobs, S.S., ed. Oceanology of the Antarctic continental shelf. Washington, DC, American Geophysical Union, 203-226. (Antarctic Research Series, 43.) 